\title{
Distribution and metabolism of intravenously administered trefoil factor $2 /$ porcine spasmolytic polypeptide in the rat
}

\author{
S S Poulsen, J Thulesen, E Nexø, L Thim
}

\begin{abstract}
Background-Trefoil peptides are secreted by mucus producing cells in the gastrointestinal tract and are supposed to be involved in oligomerisation processes of the mucin glycoproteins in the lumen. Endocrine functions have also been suggested.
\end{abstract}

Aims-To target possible binding sites for iodine-125 labelled porcine spasmolytic polypeptide ( $\mathrm{pSP}$ ) in an in vivo rat model. Methods- ${ }^{125} \mathrm{I}-\mathrm{pSP}$ was given by intravenous injection to female SpraqueDawley rats. The distribution of ${ }^{125} I-p S P$ was assessed by gamma counting of samples of organs and by autoradiography of paraffin wax embedded sections. The degradation of ${ }^{125} I-p S P$ was studied by trichloroacetic acid precipitation, and the saturability of binding by administration of excess unlabelled peptide.

Results- ${ }^{125}$ I-pSP was taken up in the kidneys and the gastrointestinal tract and was excreted almost unmetabolised in the urine. In the stomach, it could be displaced by unlabelled pSP in a dose dependent manner. Autoradiography showed grains in mucous neck cells, parietal cells, the mucus layer, and the pyloric glands of the stomach; in Brunner's glands and the Paneth cells in the small intestine; and in cells in the lower part of the crypts in the colon.

Conclusions $-{ }^{125} I-p S P$ from the circulatory system is taken up by mucus producing cells in the gastrointestinal tract. The binding can be displaced by nonradioactive $\mathrm{pSP}$, suggesting the presence of a receptor.

(Gut 1998;43:240-247)

Keywords: trefoil peptides; trefoil factor 2; spasmolytic polypeptide; metabolism; autoradiography; rat

Porcine spasmolytic polypeptide (pSP) belongs to a family of mucin associated gastrointestinal peptides. These peptides have been named trefoil factors (TFF) due to the existence of one or more domains in which six cysteine residues form three disulphide bonds to create a characteristic three leaved structure. ${ }^{12}$ In addition to SP (also named TFF2) the mammalian trefoil factor family also includes the breast cancer associated peptide, pS2 (also named TFF 1$)^{3}$ and intestinal trefoil factor, ITF (also named TFF3)..$^{4-6}$ Porcine SP was originally isolated from the pancreas. ${ }^{78}$ By immunohisto- chemical investigations, the peptide was localised to exocrine cells of the stomach, duodenum, and pancreas. ${ }^{9}$ Homologous peptides to porcine SP have been identified in other species. The trefoil peptide family now includes SP from pig, rat, mouse, and man, ${ }^{8}{ }^{10-13}$ which is secreted from the pyloric glands, the mucous neck cells of the corpus fundic glands, and the duodenal Brunner glands; ITF from rat, mouse, and $\operatorname{man}^{4} 5$ secreted from the intestinal goblet cells; and the $\mathrm{pS} 2$ peptide shown in the surface epithelium of the stomach from man and mouse ${ }^{313}$ (for review see Thim ${ }^{14}$ ).

The physiological role of the trefoil peptides is not yet fully elucidated. The presence of the peptides in exocrine cells in the gastrointestinal tract suggests a function in the gastrointestinal secretions. They are highly resistant to degradation by proteases, ${ }^{7}$ probably due to their compact three dimensional structure. ${ }^{15}$ They are secreted by mucus producing cells, and in the lumen they are supposed to link together the polysaccharide sidechains of mucin glycoproteins to form large, highly viscous, and resistant complexes. ${ }^{15-17}$ In accordance with this, mice with a non-functional gene encoding ITF have impaired mucosal healing in the colon ${ }^{18}$; transgenic mice that overexpress pS2 have increased resistance to mucosal damage ${ }^{19}$; and pretreatment of rats with oral SP or ITF has been shown to protect against gastric injury. ${ }^{20}$

Endocrine functions of the trefoil peptides have also been suggested. The first reports on the effects of pSP described an inhibitory effect on intestinal motility and on gastric acid secretion, ${ }^{21}$ and relaxation of the sphincter Oddi. ${ }^{22}$ Small amounts of SP are present in plasma from the pig $^{8}$ and receptor-like binding sites have been suggested from in vitro investigations on rat intestinal mucosal cell membranes for $\mathrm{SP}^{23}$ and on frozen sections from rat gastrointestinal tissues for ITF. ${ }^{24} 25$

Moreover, mice with inactivated pS2 gene developed malignant transformation in the stomach. ${ }^{26}$ Recently, it was shown that subcutaneous injections of SP in very low doses to rats protected against indomethacin induced gastric damage without inhibiting acid secretion, whereas similar doses of oral SP were without any effect. ${ }^{27}$ The effect of $\mathrm{pSP}$ was proposed to be mediated by increased cell migration, an effect which has now been shown in vitro for all three trefoil factors. ${ }^{27-29}$

In order to target possible binding sites for circulating SP in an vivo model, we have studied
Accepted for publication 18 February 1998 
Table 1 Distribution of percentage radioactivity after injection of ${ }^{125} I-p S P$ over time

\begin{tabular}{|c|c|c|c|c|c|c|}
\hline & \multicolumn{6}{|c|}{ Time (min) } \\
\hline & 2 & 6 & 15 & 45 & 240 & 24 hours \\
\hline Blood & $51(6)$ & $23(7)$ & $19(9)$ & $4(1)$ & $5(1)$ & $2(1)$ \\
\hline Gastrointestinal tract & $9(3)$ & $14(5)$ & $12(5)$ & $8(2)$ & $9(1)$ & $3(1)$ \\
\hline Kidney & $16(8)$ & $40(10)$ & $28(13)$ & $23(9)$ & $3(1)$ & $<1$ \\
\hline Urine & & & $15(7)$ & $25(11)$ & $55(19)$ & $76(16)$ \\
\hline Thyroid & $<1$ & $<1$ & $<1$ & $<1$ & $2(1)$ & $8(4)$ \\
\hline Remaining organs & $24(9)$ & $23(12)$ & $26(7)$ & $40(11)$ & $26(10)$ & $11(11)$ \\
\hline
\end{tabular}

Results are expressed as mean (SD); $n=4$.

the distribution and metabolism of intravenously administered iodine- 125 labelled pSP in the rat.

\section{Materials and methods \\ PREPARATION OF ${ }^{125} \mathrm{I}$-pSP}

pSP $100 \mu \mathrm{g}$, highly purified as previously described, ${ }^{6}$ was iodinated by Amersham International (UK), with sodium ${ }^{125}$ I-iodide, using hydrogen peroxide and lactoperoxidase. ${ }^{7}$ The specific activity obtained was $222 \mathrm{kBq} / \mu \mathrm{g}$ (6 $\mu \mathrm{Ci} / \mu \mathrm{g})$. The iodinated peptide was diluted to a radioactive concentration of $100 \mu \mathrm{Ci} / \mathrm{ml}$ with $5 \%$ lactose, $0.25 \%$ radioimmunoassay (RIA) grade bovine serum albumin, and 0.3 trypsin inhibitor units $/ \mathrm{ml}$ aprotinin, in $50 \mathrm{mM}$ sodium phosphate buffer, $\mathrm{pH} 7.4$. Before use ${ }^{125} \mathrm{I}-\mathrm{pSP}$ was diluted in $0.154 \mathrm{mmol} / 1$ saline with $1 \%$ albumin to a final concentration of $0.5 \mu \mathrm{g} / \mathrm{ml}$ (approximately $1 \times 10^{6} \mathrm{cpm} / \mathrm{ml}$ ).

TISSUE DISTRIBUTION OF ${ }^{125} \mathrm{I}$-pSP

The animal studies were approved by the Danish National Committee for Animal Studies. For quantitative studies on the distribution of ${ }^{125}$ I-pSP, 28 female Spraque-Dawley rats, weighing 250-270 g, were anaesthetised by an intraperitoneal injection of $50 \mathrm{mg} / \mathrm{kg}$ methohexital (Brietal, Lilly, USA); buprenorphine (Temgesic, Reckitt and Colman Pharmaceuticals, Hull, UK) $0.1 \mathrm{mg} / \mathrm{kg}$ subcutaneously was given as an analgesic. The abdomen was opened by a midline incision and $950 \mu$ of ${ }^{125} \mathrm{I}-$ pSP was injected into the inferior vena cava. A

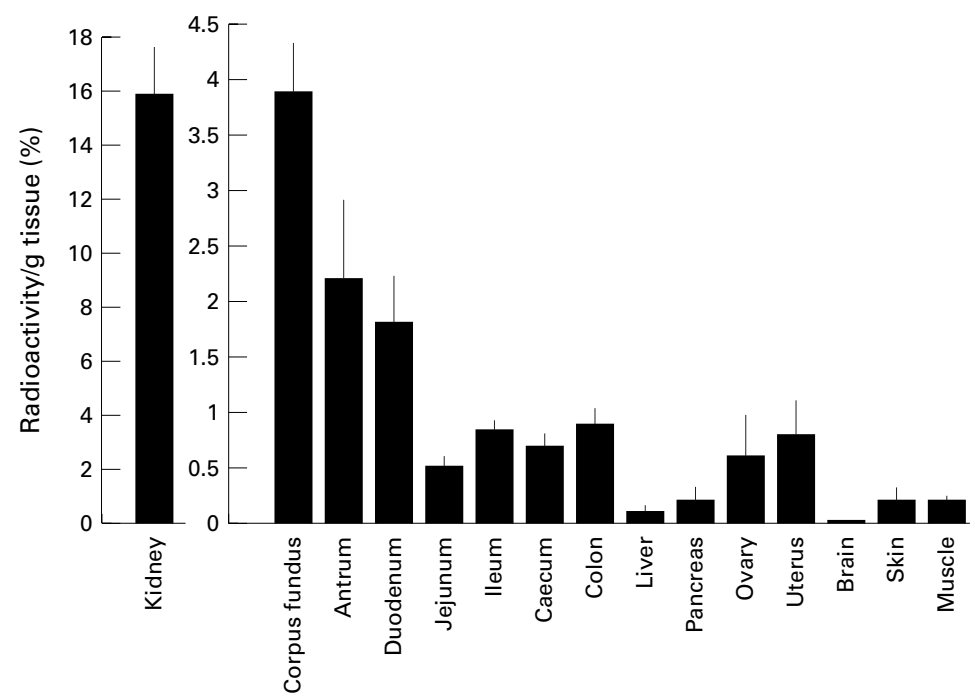

Figure 1 Uptake of radioactivity six minutes after administration of ${ }^{125} I-p S P$, measured as the percentage of total radioactivity given to each rat. Results expressed as mean (SD); $n=4$. sample of $50 \mu \mathrm{l}$ was counted with a gamma spectrometer in order to estimate the counts given to each rat. The rats were sacrificed in groups of four after 2, 6, 15, 45, 120, and 240 minutes, and 24 hours. In the first three groups, the rats did not regain consciousness before sacrifice, whereas the rats sacrificed after 45, 120, and 240 minutes and 24 hours had the midline incision sutured and were reanaesthetised before sacrifice. For collection of urine, the rats had the urethra ligated and the bladder was emptied by cannulation at sacrifice. The 24 hour rats were placed in Bollman cages for collection of urine. When sacrificed, the rats were connected to an animal respirator (Harvard Apparatus, Massachusetts, USA) and the thorax was opened. Blood $(1 \mathrm{ml})$ was drawn from the right cardiac ventricle and urine was collected from the bladder. The vascular system was then perfused through the left cardiac ventricle (outlet through the right atrium) with $150 \mathrm{ml}$ saline to ensure removal of blood from the organs. The effluent was collected. The organs were removed and weighed and samples of the organs with known weight, a sample of blood, a sample of the effluent saline, and the $50 \mathrm{ml}$ sample of the ${ }^{125} \mathrm{I}-$ pSP injected into each rat were counted in a gamma spectrometer (Wallach, LKB, UK).

To investigate whether the metabolism of pSP is influenced by the dose given and the binding of pSP is saturable, $0.05 \mathrm{mg}, 1 \mathrm{mg}$, or $10 \mathrm{mg}$ unlabelled pSP was given together with ${ }^{125} \mathrm{I}$-pSP to three rats for each dose. The rats were sacrificed after 15 minutes.

Tissues investigated were liver, pancreas, oesophagus, the various parts of the stomach, the duodenum, jejunum, ileum, caecum, colon, submandibular gland, lung, brain, heart, adipose tissue, skeletal muscle, uterus, ovary, kidney, urinary bladder, adrenal gland, thyroid gland, and skin. The radioactivity was calculated as the percentage of the total radioactivity administered to each rat present in each organ or as the percentage of total radioactivity per gram tissue in each organ.

\section{AUTORADIOGRAPHY}

After perfusion with saline (see above) two rats in each group $(0,2,6,15,45,120$, and 240 minutes) were fixed by perfusion for two minutes with ice cold freshly prepared $4 \%$ glutaraldehyde in $0.04 \mathrm{~mol} / 1$ phosphate buffer, $\mathrm{pH}$ 7.4. The same tissues as described above were investigated. The tissues were removed and postfixed for 24 hours in $70 \%$ ethanol, dehydrated, and embedded in paraffin wax. Histological sections of $5 \mu \mathrm{m}$ were coated with Ilford K2 liquid autoradiographic emulsion diluted $1 / 1$ in $300 \mathrm{mM}$ ammonium acetate, placed in light tight boxes, and stored at $-80^{\circ} \mathrm{C}$ for four or seven weeks. The autoradiographs were developed in an Ilford developer for five minutes at $17^{\circ} \mathrm{C}$ and fixed in Kodak fixer for five minutes. The sections were stained slightly with haematoxylin and examined by light microscopy. 

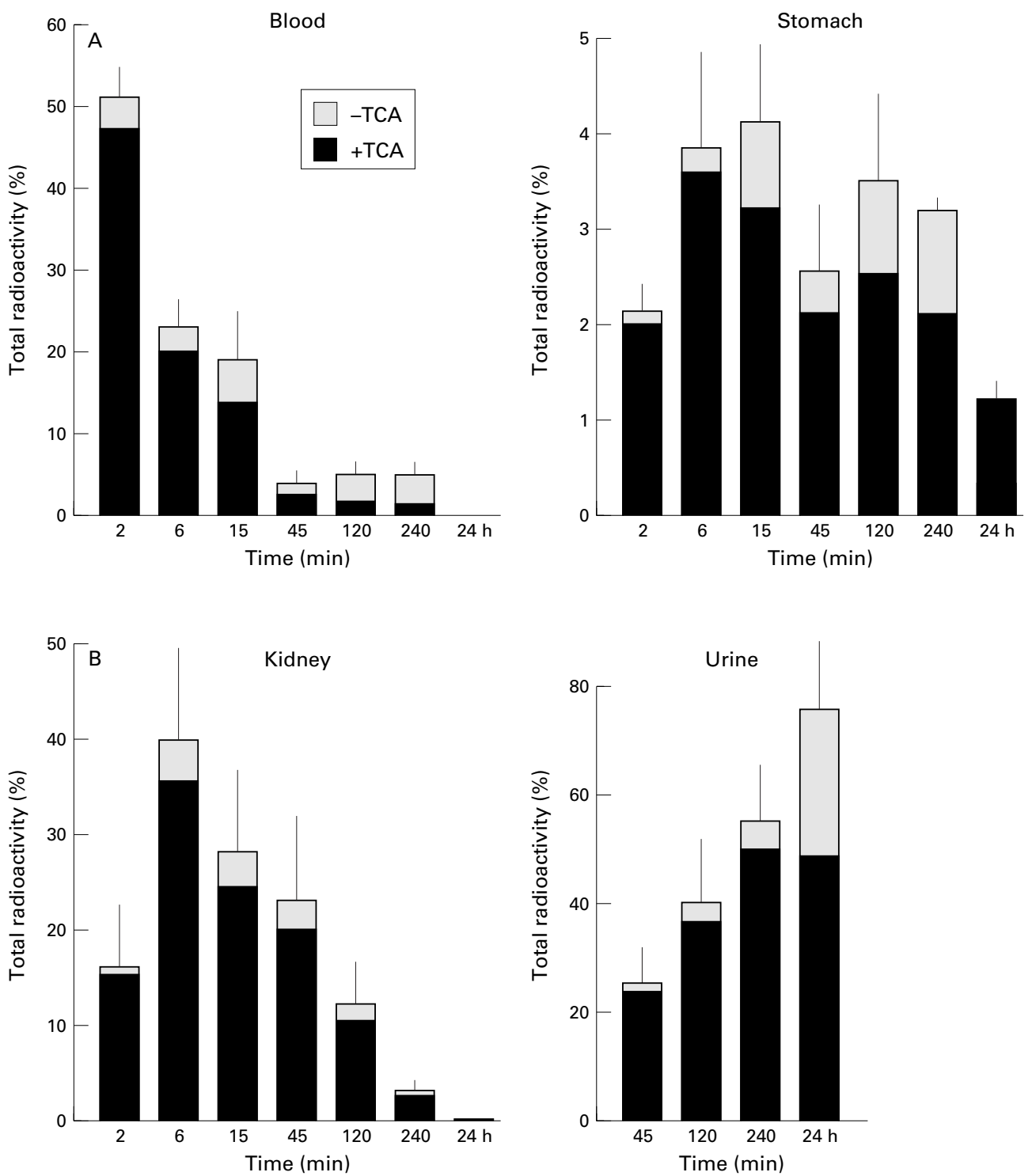

Figure 2 Percentage of total radioactivity given to each rat present in blood and the body of the stomach $(A)$ and in the kidney and urine $(B)$ at various times after administration of ${ }^{125} I-p S P$. The black part of the bars indicates the fraction which can be precipitated by TCA and the grey part the fraction which cannot be precipitated. Results expressed as mean (SD); $n=4$.

BIOCHEMISTRY

Urine, plasma, and tissue samples were collected from two animals in each group (see above) and kept frozen at $-20^{\circ} \mathrm{C}$ for analysis of peptide bound label by trichloroacetic acid (TCA) precipitation. Tissue extract was prepared by homogenising 500-1000 mg tissue in $4 \mathrm{ml} \mathrm{0.1} \mathrm{M} \mathrm{phosphate} \mathrm{buffer,} 1 \%$ human albumin (Beringwerke, Germany), $\mathrm{pH}$ 8.0. Samples $(500 \mathrm{ml}$ tissue extract, plasma in dilution 1 +4 , urine in dilution $1+249$ or ${ }^{125} \mathrm{I}-\mathrm{pSP}$ ) were counted in a gamma spectrometer (Gambit). Ice cold $20 \%$ TCA $(1 \mathrm{ml})$ was added to each sample. The samples were mixed and incubated on ice for 30 minutes. The pellet obtained after centrifugation for 20 minutes at $4^{\circ} \mathrm{C}$ and $2100 \mathrm{~g}$ was counted. The fraction precipitated with TCA was calculated by dividing the counts present in the pellet by the counts present in the sample. The fraction of ${ }^{125} \mathrm{I}-\mathrm{pSP}$ precipitated by TCA was 0.94 (mean, $n=3$ ).

\section{Results}

METABOLISM AND DISTRIBUTION

Table 1 shows the time relations for the distribution of injected radioactivity in the blood, the urinary system, the gastrointestinal tract, and the thyroid gland. After six minutes, $77 \%$ of the radioactivity had disappeared from the blood and after 45 minutes only small amounts could be detected. A major part of the peptide - up to $40 \%$ - was taken up by the kidneys and excreted in urine. The gastrointestinal tract (stomach, small intestine, caecum, and colon) also accumulated a considerable amount (14\%) of the peptide, and the clearance from the gastrointestinal tract was more protracted than from the kidneys. No other tissues seemed to concentrate the peptide. Only small amounts were detected in the liver $(0.8 \%)$ and the brain $(0.01 \%)$.

In order to compare the ability of the different tissues to concentrate ${ }^{125} \mathrm{I}$-pSP, the radioac- 

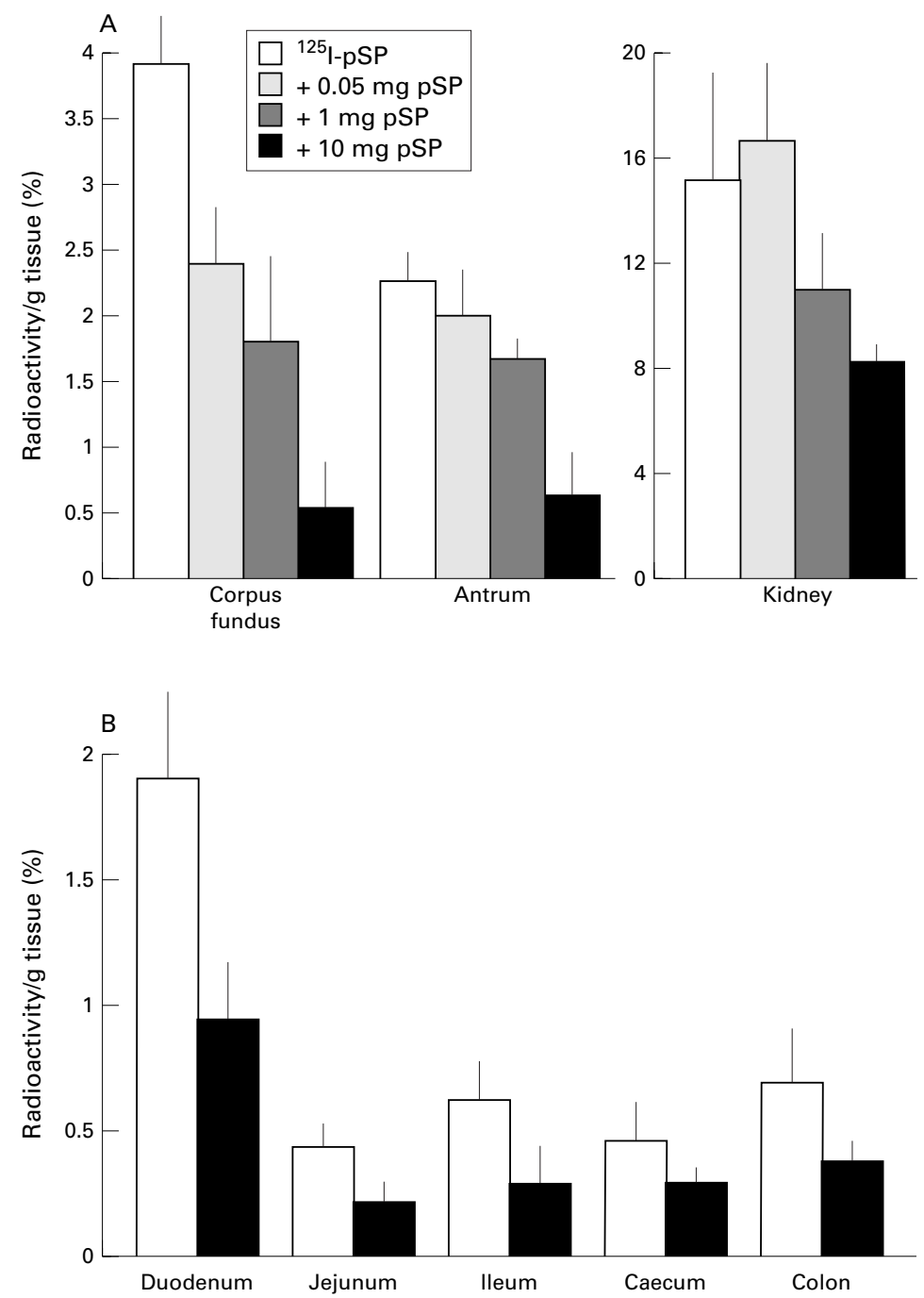

Figure 3 (A) Effect of pretreatment with increasing doses of non-iodinated $p S P$ on uptake of radioactivity in the stomach and kidney in rats sacrificed 15 minutes after administration of ${ }^{125} I-p S P$. Uptake of ${ }^{125} I-p S P$ is indicated as the percentage of total radioactivity given to each rat, taken up per $g$ tissue. (B) Effect of pretreatment with the maximum dose of $10 \mathrm{mg}$ non-iodinated $\mathrm{pSP}$ on uptake of radioactivity in the intestinal system. Results expressed as mean (SD); $n=3$.

tivity was expressed as a percentage of injected dose per gram tissue (fig 1). The major part of the radioactivity was present in the blood, kidney, and gastrointestinal tract. For a rat weighing about $250 \mathrm{~g}$, the weight of these organs represents approximately $30 \mathrm{~g}$. Thus, after six minutes, $23 \%$ of the total radioactivity (table 1 ) was left for the remaining $220 \mathrm{~g}$ of the rat or $0.1 \%$ per $g$ tissue. The radioactivity taken up by the kidney was $16 \%$ per g tissue or almost 160 times as much as in the remaining tissues. In the gastrointestinal tract, the highest uptake was in the body and pyloric part of the stomach and the duodenum. The uptake in the body of the stomach was $4 \%$ per $\mathrm{g}$ tissue or 40 times that of the remaining group of tissues. The jejunum, ileum, caecum, and colon also had an increased uptake, as did the uterus and ovaries.

Figure 2 shows the fraction of ${ }^{125} \mathrm{I}-\mathrm{pSP}$ in tissues from the stomach, kidney, plasma, and urine, which could be precipitated by TCA, combined with the variation in radioactivity during the study period. In plasma, the fraction which could be precipitated by TCA gradually

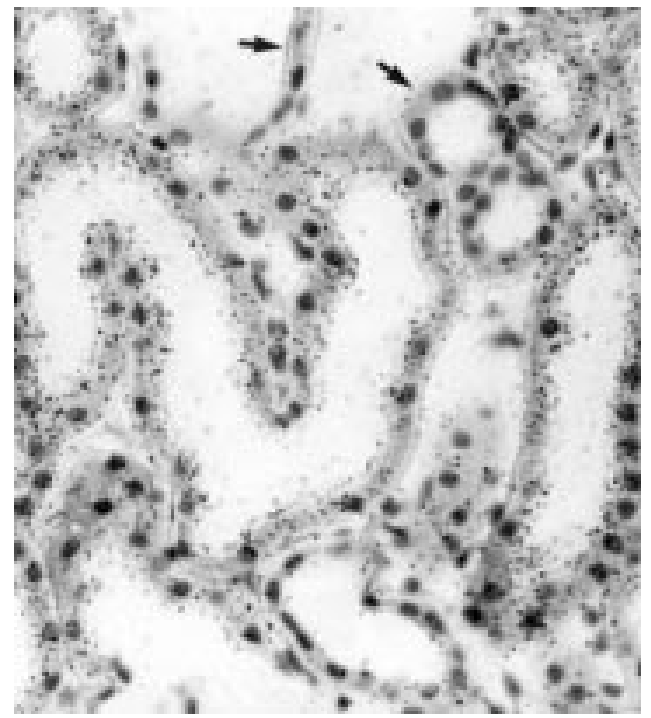

Figure 4 Autoradiograph of the kidney 15 minutes after administration of ${ }^{125} I-p S P$. Grains are localised to the brush border and the cytoplasm of the cells of the proximal convoluted tubules. Arrows indicate distal tubules. Original convoluted tubules. A
magnification $\times 480$.

decreased to 0.72 after 15 minutes and 0.30 after 240 minutes. In the stomach, most of the radioactivity could also be precipitated after 240 minutes, and the stomach had protracted binding of radioactivity. After 24 hours, the content of radioactivity was still $1 \%$ of total radioactivity per gram tissue even though $76 \%$ of radioactivity had been excreted in urine. ${ }^{125} \mathrm{I}-$ pSP seemed only to be metabolised to a minor degree in the urinary system. In the kidney, the fraction of peptide precipitated with TCA hardly decreased, and in urine the main part of the radioactivity could be precipitated, 0.88 after 240 minutes and 0.64 after 24 hours.

When ${ }^{125} \mathrm{I}-\mathrm{pSP}$ (approximately $1 \mu \mathrm{g}$ ) was given together with non-radioactive $\mathrm{pSP}$, there was a dose dependent reduction in the uptake of radioactivity in the body and pyloric part of the stomach and in the kidney (fig $3 \mathrm{~A}$ ). In the various parts of the intestine, there was a reduction only after injection of $10 \mathrm{mg}$ pSP (fig $3 \mathrm{~B})$. There was no reduction in uptake in the pancreas, ovaries, or uterus.

\section{AUTORADIOGRAPHY}

In the kidneys, the label was found to be present in cells of the proximal tubules both at the level of the brush border and in the cytoplasm (fig 4). After two and six minutes, grains were observed only in the first part of the proximal tubule. Later grains were also observed in the first part of the loop of Henle and in cells of some of the collecting tubules of the medulla.

Grains were found in all three parts of the stomach localised almost exclusively in mucus producing cells. In the body, a strong uptake was observed in the neck part of the glands (figs 5A and 6A). Grains were localised mainly in the mucous neck cells, but also in the cytoplasm of some of the parietal cells in the same region (fig 5B). There was no uptake in the surface epithelial cells, the parietal cells, or zymogenic cells in the main part of the glands, 

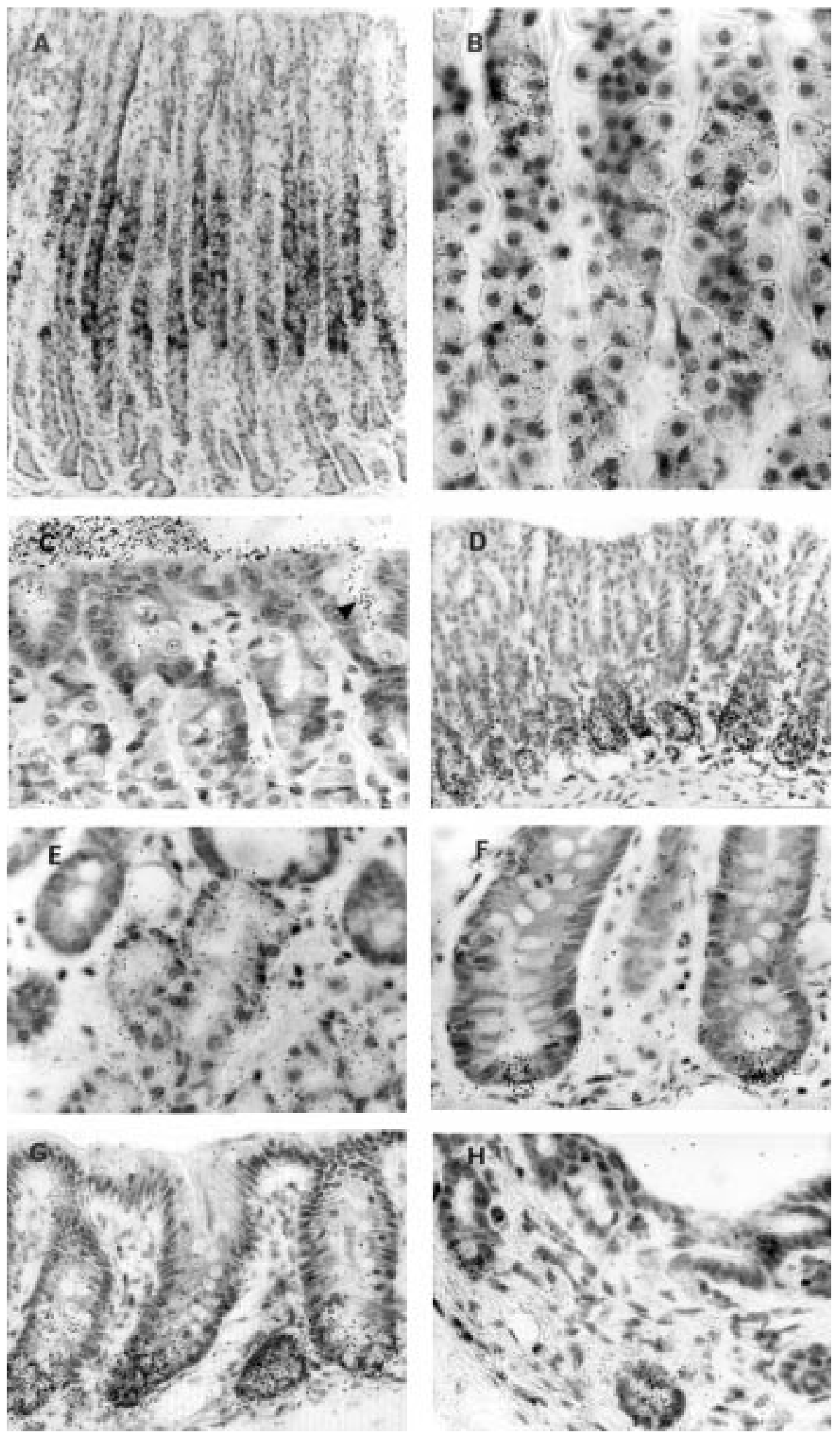

Figure 5 Autoradiographs showing uptake of radioactivity in various parts of the gastrointestinal tract. (A) The mucosa of the body of the stomach 15 minutes after administration of ${ }^{125} I-p S P$. Grains are localised to the neck part of the gastric glands, mainly to the mucous neck cells. (B) Larger magnification of the neck part showing grains also in the parietal cells. (C) The mucosal surface of the body of the stomach 120 minutes after administration of ${ }^{125}$ I-pSP. Grains are observed in the lumen of the gastric pits (arrow) and on the luminal surface. (D) The pyloric part of the stomach with grains in the pyloric glands. (E) The duodenum. Grains are localised to Brunner's glands whereas the epithelium of the crypts in the upper part of the picture is negative. (F) The ileum. Grains are localised to the basal part but also in the cytoplasm of the Paneth cells in the bottom of the crypts of Lieberkühn. (G) The colon. Grains are concentrated in the lower part of the crypts. (H) The pancreas. Part of a large excretory duct with grains in small basal buds of the epithelium. Original magnification: $A, \times 100 ; B, \times 550 ; D, \times 175 ; C, E, F, G, H, \times 440$. 

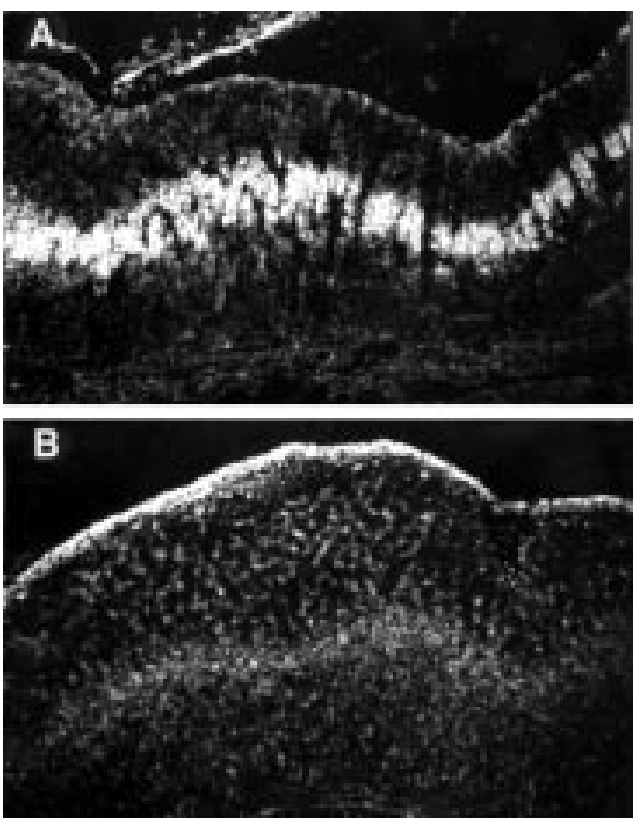

Figure 6 Autoradiographs showing the effect of excess unlabelled pSP on the localisation of radioactivity in the body of the stomach. Dark field microscopy. (A) The mucosa of the body of the stomach 15 minutes after administration of ${ }^{125} I-p S P$. Grains are localised to the neck part of the gastric glands. (B) The mucosa 15 minutes after administration of ${ }^{125} \mathrm{I}-\mathrm{p} S P$ together with $10 \mathrm{mg}$ unlabelled pSP. Grains are now localised almost exclusively to the luminal surface of the mucosa, whereas the neck part of the glands only appears as a faint transverse band. Original magnification $\times 70$.

or in the muscle layers. The amount of grains in the neck part of the glands only decreased slowly and grains were observed even after 24 hours. Increasing amounts of grains were observed in the lumen of the glands, the gastric pits and especially in the mucus layer in rats sacrificed after more than 15 minutes (fig 5C). When ${ }^{125} \mathrm{I}-\mathrm{pSP}$ was given together with unlabelled pSP, the grains were observed also in the mucus layer after 15 minutes, especially after the large dose of unlabelled pSP (fig 6B).

In the pyloric part of the stomach and the cardia, grains were localised exclusively in the cytoplasm of cells in the mucus producing glands (fig 5D). There was no binding in the surface epithelium, the muscle layers, or in any ganglionic cells.

In the duodenum, the grains were localised in the mucus producing cells of the secretory acini of Brunner's glands (fig 5E). Primarily, the grains were outside the cells, but after 15 minutes they were also observed intracellularly. In the jejunum and ileum, label was localised in the Paneth cells in the bottom of the crypts of Lieberkühn (fig $5 \mathrm{~F}$ ); all other structures were negative, including the small intestinal goblet cells. In the caecum and colon, the grains were concentrated in the epithelium in the lower part of the crypts (fig 5G), primarily in the absorptive cells but also in some goblet cells. The upper parts of the crypts and the surface epithelium including the goblet cells were negative.

Finally, a few grains were found in the pancreas. In the large excretory ducts of the pancreas, grains were localised very distinctly in the basal buds of the epithelium (fig $5 \mathrm{H}$ ). It was not possible to localise grains to any particular structures in the ovary or uterus.

In sections of tissues from rats not given ${ }^{125} \mathrm{I}-$ pSP, there was a little background staining seen as evenly distributed grains with the same intensity within the tissue as outside the tissue and without concentration to any particular structures.

\section{Discussion}

In the present study, ${ }^{125} \mathrm{I}-\mathrm{pSP}$ was given intravenously to rats and the metabolism of the peptide and possible target sites in the organs for SP are described. The clearance of ${ }^{125} \mathrm{I}-\mathrm{pSP}$ from blood was slow. When ${ }^{125}$ I-epidermal growth factor (EGF) was investigated in a study with the same design, ${ }^{30}$ only $7 \%$ of radioactivity was left in blood after two minutes, in comparison with the findings in the present study of $52 \%$ of pSP after two minutes and $19 \%$ after 15 minutes. The explanation for this difference may be that $\mathrm{pSP}$ was not taken up by the liver, which accumulates and degrades the major part of injected EGF. ${ }^{30}$ Furthermore, pSP is highly resistant to degradation by proteases $^{727}$ and therefore less exposed to enzymatic degradation. This is substantiated by the findings that the percentage of radioactivity which could be precipitated with TCA in the tissues decreased very slowly, and although pSP was taken up by the cells in the proximal tubules of the kidney, the major part of radioactivity excreted in urine could be precipitated with TCA.

The possibility of endocrine effects of SP was suggested recently when it was shown that subcutaneously administered SP is able to protect rats against the development of indomethacin/ stress induced gastric ulcerations ${ }^{27}$ in a dose of less than $1 \%$ of the dosage found to be effective following oral administration. ${ }^{20}$ The presence of a receptor has been suggested from in vitro investigations on rat intestinal mucosal cell membranes, ${ }^{23}$ and in frozen sections binding of ${ }^{125} \mathrm{I}-\mathrm{ITF}$ was localised to the collecting ducts of the kidney, the neck region, and surface epithelium of the stomach, and to the crypt epithelium of the small intestine and the colon. $^{24} 25$

Endocrine effects of SP implicate the presence of a cellular receptor localised basolaterally which allows uptake of peptide secreted via the endocrine or paracrine pathways. In the present study, we have used an in vivo model to show binding sites for ${ }^{125} \mathrm{I}-\mathrm{SP}$. The peptide is distributed via the circulatory system and presented to the basolateral part of the cells. Furthermore, direct binding of radiolabelled peptide to intracellular mucus due to the high affinity of the peptide to the mucin glycoproteins is avoided. Our findings support the assumption that the uptake of ${ }^{125} \mathrm{I}-\mathrm{pSP}$ in the gastrointestinal tract is receptor mediated, as the uptake of radioactivity could be displaced with non-radioactive $\mathrm{pSP}$, with a reduction at the maximum dose to $13 \%$ and $28 \%$ in the body and the pyloric part of the stomach, respectively, and to approximately $50 \%$ in the rest of the intestinal tract. 
In the gastrointestinal tract, the radioactivity seemed to be localised primarily in mucus producing cells, which are immunoreactive to SP themselves, ${ }^{10}{ }^{20}$ namely the mucous neck cells, the cells of the pyloric and cardia glands, and the duodenal Brunner's glands. The surface epithelium of the stomach, which produces mucus and the other trefoil peptide, $\mathrm{pS} 2,{ }^{3}$ and the small intestinal goblet cells, which produce $\mathrm{ITF}_{,}{ }^{4}$ did not bind radioactive $\mathrm{pSP}$. Thus, $\mathrm{pSP}$ seems to bind to the same cells that are immunoreactive to the peptide, but not to the cells which are immunoreactive to the other trefoil peptides. The binding seems to be receptor mediated - or at least it can be displaced by excess amounts of unlabelled pSP. The interpretation of these results is not obvious. It may, however, shed new light on the results of Jeffrey $e t a l,{ }^{10}$ who found a discrepancy between localisation of the rat SP in the stomach, determined by immunohistochemistry, and the rat SP mRNA determined by in situ hybridisation. In the body of the stomach, they found the mRNA in the deepest part of the gastric pits, where the immature cells are localised, in contrast to the immunoreactive peptide, which was present in the neighbouring mucous neck cells. In the antrum, the mRNA was found in the deepest part of the pits and in the upper part of the glands, whereas the immunoreactive peptide was present in the deepest part of the glands. It was suggested that the mRNA was present in the immature cells producing the peptide and later when the cells had migrated downwards and developed to mature glandular cells, they still contained the peptide. Another explanation which would fit with both the findings of Jeffrey et al and the findings in the present study of high affinity basolateral uptake of ${ }^{125} \mathrm{I}-\mathrm{pSP}$ by the cells which express the peptide immunohistochemically, but not the mRNA at in situ hybridisation, would be that the SP is actually produced in the cells which express the mRNA, and that the peptide is secreted in a paracrine manner basolaterally and thereafter taken up by the mucous neck cells of the body of the stomach and likewise for the mucous glands of the antrum. It would be interesting to investigate whether the other trefoil peptides also bind specifically to the mucus producing cells that are immunoreactive to each particular peptide.

A functional role of the trefoil peptides in the luminal secretions of the gastrointestinal tract seems well established. They are localised to exocrine, most often mucus producing cells. ${ }^{45} 91031$ In the lumen, they have been proposed to be involved in oligomerisation processes of the mucin polysaccharide molecules, which lead to formation of gel-like, high viscosity mucus. ${ }^{16}{ }^{17}$ High concentrations of SP have been measured in rat gastric mucus, ${ }^{10}$ immunoreactive SP has been detected in the mucus layer, ${ }^{10}$ and overexpression of $\mathrm{pS} 2$ in mice increases the resistance to intestinal damage, ${ }^{18}$ whereas mice lacking ITF have impaired defence. ${ }^{18}$ In the damaged mucosa, the trefoil peptides have been colocalised with EGF in the recently described "ulcer associated cell lineage". ${ }^{32-36}$
The role of the trefoil peptides in the gastrointestinal lumen is further substantiated by the experimenal studies showing that intragastrically administered trefoil peptides in a dose dependent manner protect against gastric injury in rats, ${ }^{20}$ indicating that orally administered SP is taken up by the mucus layer.

The protective effect of parenterally administered SP might be caused by other mechanisms than an effect related to the mucus layer; for example, an effect on gastric emptying, a growth factor-like effect, stimulation of cell migration, ${ }^{27} 3435$ or inhibition of acid secretion (although the latter was investigated with negative results ${ }^{27}$ ). The autoradiographic findings in the present study, however, suggest an interpretation which might be compatible with the finding of a protective effect of both luminally and parenterally administered SP. In rats sacrificed within the first 15 minutes after ${ }^{125} \mathrm{I}-\mathrm{pSP}$ administration, grains were found only in the mucous neck cells and some of the parietal cells in the body of the stomach. In the rats sacrificed later than that, increasing amounts of grains were also localised in the lumen of the glands, the lumen of the gastric pits, and in the mucus layer. Furthermore, the same phenomenon was observed after 15 minutes, when excess unlabelled pSP was given together with ${ }^{125} \mathrm{I}-\mathrm{pSP}$. This was also seen after the dose of 50 $\mu \mathrm{g}$ unlabelled pSP, which is a dose similar to that used by Playford et $a l^{7}$ to prevent indomethacin induced gastric ulceration. Final conclusions cannot be deduced from the present findings but they suggest receptor mediated uptake of SP and subsequent exocrine secretion, which is unusual for a peptide. The trefoil factors are small peptides with the exceptional property that they are very resistant to degradation by proteases and thereby not exposed to degradation by intracellular enzymes. What could happen in the mucous neck cells (or neighbouring parietal cells) might be compared with the situation in the kidneys. Up to $40 \%$ of injected radioactivity is taken up by the kidneys (six minutes), primarily by the proximal tubules. Grains are present in the brush border and cytoplasm indicating that the radioactivity is taken up by the cells. After four hours only 3\% is present in the kidneys, $25 \%$ is now in the urine, and $88 \%$ of this can be precipitated with TCA. Blood accounts for $4 \%$. Thus it seems that the tubular cells of the kidney excrete the major part of the SP without degradation. The intracellular localisation of SP and the possible way of excretion should be studied by autoradiography at the electron microscopical level.

Endogenous trefoil peptides are secreted from the gastric glands and the surface epithelium together with mucus and thereby end up in the most recently secreted inner part of the mucus layer. Injected pSP is taken up by the stomach and if a significant part of the peptide ends up in the mucus layer in the same way as endogenous SP, this might offer an explanation for the mechanism of the protective effect of parenteral SP and also the rather low dosage, in comparison to oral $\mathrm{SP}$, which is necessary to obtain the effect. When SP is given orally, the 
luminal side of the mucus layer, which is the part going to be desquamated next, is exposed to the cross linking effect of the SP and possibly only a minor proportion penetrates into the deeper layers.

In conclusion, we have developed a system in the rat whereby circulating SP is targeted to its binding sites and possible sites of action in the gastrointestinal tract. The binding can be displaced by non-radioactive pSP, suggesting the presence of a receptor. This intensifies the need to identify and characterise receptors to the trefoil peptides.

This study was supported by the Biotechnology Centre for Celular Communication and the Danish Medical Research Council. The technical assistance of Jette Schousboe and Jette Hansen, and the photographic assistance of Grazyna Poulsen is warmly acknowledged.

1 Thim L. A new family of growth factor-like peptides. "Trefoil" disulphide loop-structures as a common feature in breast cancer associated peptide (pS2), pancreatic spasmolytic polypeptide (PSP) and frog skin peptides (spasmolysins). FEBS Lett 1989;250:85-90.

2 Wright NA, Hoffmann W, Otto WR, et al. Rolling in the clover: trefoil factor family (TFF)-domain peptides, cell migration and cancer. FEBS Lett 1997;408:121-3.

3 Rio MC, Bellocq JP, Daniel JY, et al. Breast cancerassociated pS2 protein: synthesis and secretion by normal stomach mucosa. Science 1988;241:705-8.

4 Suemori S, Lynch-Devaney K, Podolsky DK. Identification and characterization of rat intestinal trefoil factor: tissueand characterization of rat intestinal trefoil factor: tissueand cell-specific member of the

5 Podolsky DK, Lynch-Devaney K, Stow JL, et al. Identification of human intestinal trefoil factor: goblet cell-specific expression of a peptide targeted for apical secretion. $\mathcal{F}$ Bio Chem 1993;268:6694-702 (Erratum: 268:12230).

6 Hauser F, Poulsom R, Chinery R, et al. hP1.B, a human $\mathrm{P}$-domain peptide homologous with rat intestinal trefoil factor, is expressed also in the ulcer-associated cell lineage and the uterus. Proc Natl Acad Sci USA 1993;90:6961-5.

7 Jørgensen KH, Thim L, Jacobsen HE. Pancreatic spasmolytic polypeptide (PSP): I. Preparation and chemical characterization of a new polypeptide from porcine pancreas. Regul Pept 1982;3:207-19.

8 Thim L, Jørgensen KH, Jørgensen KD. Pancreatic spasmolytic polypeptide (PSP): II. Radioimmunological determination of PSP in porcine tissues, plasma and pancreatic nation of PSP in porcine tissues,
juice. Regul Pept 1982;3:221-30.

9 Rasmussen TN, Raaberg L, Poulsen SS, et al. Immunohistochemical localization of pancreatic spasmolytic polypeptochemical localization of pancreatic spasmolytic polyp
tide (PSP) in the pig. Histochemistry 1992;98:113-19.

tide (PSP) in the pig. Histochemistry 1992;98:113-19.
10 Jeffrey GP, Oates PS, Wang TS, et al. Spasmolytic jeffrey GP, Oates PS, Wang TS, et al. Spasmolytic polypeptide: a trefoil peptide secreted by
cells. Gastroenterology 1994;106:336-45.

11 Thim L, Norris K, Norris F, et al. Purification and characterization of the trefoil peptide human spasmolytic polypeptide (hSP) produced in yeast. FEBS Lett 1993;318 345-52.

12 Tomasetto C, Rio M, Gautier C, et al. HSP, the domain duplicated homolog of $\mathrm{pS} 2$ protein, is co-expressed with pS2 in stomach but not in breast carcinoma. EMBO $\mathscr{f}$ 1990;9:407-14.

13 Lefebvre O, Wolf C, Kedinger $\mathrm{M}$, et al. The mouse one $\mathrm{P}$-domain (pS2) and two P-domain (mSP) genes exibit distinct patterns of expression. F Cell Biol 1993;122:191-8.

14 Thim L. Trefoil peptides: a new family of gastrointestinal molecules. Digestion 1994;55:353-60.

15 Gajhede M, Petersen TN, Henriksen A, et al. Pancreatic spasmolytic polypeptide: first three dimensional structure of a member of the mammalian trefoil family of peptides. Structure 1993;1:253-62.
16 Kindon $\mathrm{H}$, Pothuolakis $\mathrm{H}$, Thim $\mathrm{L}$, et al. Trefoil peptide protection of intestinal epithelial barrier function: cooperative interaction with mucin glycoprotein. Gastroenterology 1995;109:515-23.

17 Hoffman W, Hauser F. The P-domain or trefoil motif: a role in renewal and pathology of mucous epithelium? Trends Biol Sci 1993;28:239-43.

18 Playford RJ, Marchbank T, Goodlad RA, et al. Transgenic mice that overexpress the human trefoil peptide pS2 have increased resistance to intestinal damage. Proc Natl Acad Sci 1996;93:2137-42.

19 Mashimo H, Wu DC, Podolsky DK, et al. Impaired defense of intestinal mucosa in mice lacking intestinal trefoil factor. Science 1996;274:262-5.

20 Babyatsky M, Debeaumont M, Thim L, et al. Oral trefoil peptides protect against ethanol and indomethacininduced gastric injury in rats. Gastroenterology 1996;110: 489-97.

21 Jørgensen KD, Diamant B, Jørgensen KH, et al. Pancreatic spasmolytic polypeptide (PSP): III. Pharmacology of a new porcine pancreatic polypeptide with spasmolytic and gastric acid secretion inhibitory effects. Regul Pept 1982;3: gastric acic $231-43$.

22 Rey JF, Greff M, Picaso J. Effect of pancreatic spasmolytic polypeptide (PSP) on the mobility of the sphincter Oddi. Gastrointest Endosc 1984;30:161-2.

23 Frandsen EK, Jørgensen KH, Thim L. Receptor binding of pancreatic spasmolytic polypeptide (PSP) in rat intestinal mucosal cell membranes inhibits the adenyl cyclase activity. Regul Pept 1986;16:291-7.

24 Chinery R, Poulsom R, Elia G, et al. Expression and purification of a trefoil motif in a beta-galactosidase fusion protein and its use to search for trefoil-binding sites. Eur 7 Biochem 1993;212:557-63.

25 Chinery R, Cox HM. Immunoprecipitation and characterization of a binding protein specific for the peptide, intestinal trefoil factor. Peptides 1995;16:749-55.

26 Lefebvre O, Chenard MP, Masson R, et al. Gastric mucosa abnormalities and tumorigenesis in mice lacking intestinal trefoil factor. Science 1996;274:262-5.

27 Playford RJ, Marchbank T, Chinery R, et al. Human spasmolytic polypeptide is a cytoprotective agent that stimulates cell migration. Gastroenterology 1995;108:10816.

28 Williams R, Stamp GWH, Gilbert C, et al. pS2 transfection of murine adenocarcinoma cell line 410.4 enhances dispersed growth pattern in a 3-D collagen gel. $\mathcal{f}$ Cell Sci 1996;109:63-71.

29 Dignass A, Lynch-Devaney K, Kindon K, et al. Trefoil peptides promote epithelial migration through a transforming growth factor beta-independent pathway. $\mathcal{F}$ Clin Invest 1994;94:376-83.

30 Jørgensen PE, Poulsen SS, Nexø E. Distribution of i.v. administered epidermal growth factor in the rat. Regul Pept 1988;23:161-9.

31 Hanby MA, Poulsom R, Singh S, et al. Spasmolytic peptide is a major antral peptide: distribution of the trefoil peptides human spasmolytic polypeptide and pS2 in the stomach. Gastroenterology 1993;105:1110-16.

32 Ashwood P, Chinery R, Alison $\mathrm{M}$, et al. Spasmolytic polypeptide, intestinal trefoil factor, EGF and TGF alfa are expressed sequentially during healing of cryoprobe induced gastric ulcers in rats. [abstract] Gut 1993;34:S50.

33 Wright NA, Poulsom R, Stamp GW, et al. Trefoil peptide gene expression in gastrointestinal epithelial cells in inflammatory bowel disease. Gastroenterology 1993;104:1220.

34 Rio MC, Chenard M-P, Wolf C, et al. Induction of pS2 and hSP genes as markers of mucosal ulceration of the digestive tract. Gastroenterology 1991;100:375-9.

35 Wright NA, Poulsom R, Stamp GW, et al. Epidermal growth factor (EGF/URO) induces expression of regulatory peptides in damaged human gastrointestinal tissues. $\mathcal{7}$ Pathol 1990;162:279-84.

36 Alison MR, Chinery R, Poulsom R, et al. Experimental ulceration leads to sequential expression of spasmolytic polypeptide, intestinal trefoil factor epidermal growth factor and transforming growth factor $\alpha$ mRNA in the rat stomach. F Pathol 1995;175:404-14. 